\title{
A crise da educação especial: uma reflexão política e antropológica
}

\author{
Paulo Ricardo Ross
}

\begin{abstract}
RESUMO
Em face das crescentes exigências pela implementação da Educação Inclusiva, proclamada como "Educação para Todos", independentemente da natureza ou severidade das necessidades educacionais especiais que possam apresentar determinados alunos, este trabalho analisa a concepção de homem, sociedade e educação, apresentada por professores da rede pública e privada - Ensino Fundamental e Médio - em relação a essas necessidades ditas especiais.

Pode-se afirmar que as crises do Estado e da Educação Especial coincidem com a supremacia e o império do mercado cujas leis desconsideram a História, a Política, o Humano e as desigualdades sociais tomando-as, simplesmente, como naturais. A apologia do mercado, a ênfase à competição e a redução do cidadão às categorias de consumidor ou de oneroso para o Estado são escamoteadas em nome da proclamação da solidariedade civil e da organização econômica socialmente responsável.

Palavras-chave: Educação Especial, Educação Inclusiva, Necessidades Especiais.
\end{abstract}

\begin{abstract}
Due to increasing demand for the Inclusive Education implementation, named as "Education for everyone", no matter what kind of special educational needs some students might have, this paper analyses men's concepts, society and education, presented by teachers from public and private schools - Primary School and High School - based upon the so called "special needs". State and Special Education crises coincide with the supremacy of market whose laws are not concerned with History, Politics, the Human Being and Social Prejudice, and consequently taking them for granted. Market apology, competition emphasis and the citizen considered just as a consumer and costly to the State are disguised in the name of a civil solidarity and responsible for a socially economic organization.

Key-words: Special Education, Inclusive Education, Special Needs.
\end{abstract}

\section{Introdução}

É notícia comum nos debates teóricos sobre educação e seus determinantes sociais, econômicos, políticos e culturais a crise da educação especial. Com efeito, crise, vem do latim crisis, que significa quebra, transformação em curso "fase difícil na evolução das coisas, dos sentimentos, dos fatos; colapso; deficiência, penúria; ponto de transição entre uma época de prosperidade e outra de depressão, ou vice-versa." (FERREIRA, 1993, p. 154) A idéia de crise põe em xeque os paradigmas que interpretam os modelos de economia, de organização política de educação etc. Mas qual é a crise da educação especial? Suas causas teriam relação com as transformações mais amplas que se processam em nossa sociedade? O fenômeno da globalização estaria produzindo efeitos sobre essa modalidade de educação? Sua situação de crise seria uma manifestação positiva de sua integração e intersubjetividade científica, atribuindo-lhe maior importância e significação social? O ponto de partida para tais questionamentos pode ser tomado na insatisfação ou inconformidade que caracteriza as produções teóricas acerca desse campo.

\section{A crise de educação especial e as possibilidades da produção do novo}

A crise da educação especial seria o reflexo das teses que proclamam o fim da história, o fim da política e o fim da igualdade? Se essa for uma hipótese afirmativa pode-se inferir que a educação especial teria exercido papel de reabilitação das pessoas com deficiência visando sua plena integração na sociedade. Já com o fim do socialismo real e consequentemente das teses igualitaristas não haveria mais sentido manter a organização de um serviço especializado para o atendimento às pessoas com deficiência, tendo em vista a não realização do sonho de integração. Neste sentido, as teses inclusivistas, ao invés de serem as respostas possíveis de nosso tempo às crises paradigmáticas, passam a ser um acobertamento ideológico de algo que a 
sociedade não conseguiu realizar: a integração social de todos. A educação especial, uma vez não tendo atingido o suposto desenvolvimento ilimitado do ser humano, teria de fechar suas portas.

A crise atual é uma crise radical, quer dizer, do sentido fundamental de nossa cultura. Em termos abstratos significa a crise do nosso paradigma. Em termos concretos expressa a crise do sonho maior e da utopia que deu sentido ao mundo moderno nos últimos séculos. Qual era este sonho? O desenvolvimento ilimitado, a vontade de poder como dominação sobre os outros, sobre os povos e sobre a natureza. (BOFF, 1994, p.66)

É comum se encontrar escritos que produzam a crítica aos modelos clínicos, historicamente predominantes na educação especial. É certo, porém, que só se avança em determinado campo da ciência quando se produzem desequilíbrios. Com efeito, desequilíbrio é resultado da crítica, é a crise.

[...] mas quem se sente de algum modo responsável pela qualidade de vida de portadores de deficiência? Essa é a crise da sociedade civil a que me refiro. Uma crise de falta de perguntas e de falta de respostas. Uma crise de desleixo coletivo, com doses variáveis de leviandade, resultado da 'falta de formação' e do individualismo que nos norteia há quase dois mil anos de civilização judaico-cristã.

Como a deficiência há que se tornar uma questão social se nem chega a ser uma questão humana? (WERNECK, 1997, p. 186)

O estado de barbárie atingido pela sociedade civil, segundo relato de WERNECK, pode sofrer uma nova direção através da união dos cidadãos e de suas organizações. O que ela não explica são quais os determinantes que podem justificar as ações dos cidadãos voltadas para o altruísmo e não mais para o individualismo posto que estão situados no modo de produção capitalista, fundado no princípio da propriedade privada.

Primeiramente, é preciso ter claro que os encaminhamentos e respostas levadas a cabo para a solução da problemática da educação especial dependem necessariamente do modo como a interpretamos. Pode-se dizer, então, que, diferentes encaminhamentos e respostas são resultados de diferentes formas de interpretação da educação especial e de suas novas funções no contexto mais amplo da sociedade. Ao se optar por uma determinada ação e ao se comprometer com uma determinada concepção dessa modalidade de educação, necessariamente se põe em prática um tipo de concepção da própria deficiência e a função que a pessoa dessa condição deve exercer em nossa sociedade.

Ao voltar à tona a necessidade de explicitar as funções da educação especial, questionam-se as razões que justificaram uma forma especial de educar esses sujeitos. Acredita-se que, ao desvelar essas razões, podese reconceitualizar o que é e o que não é a educação especial hoje. A educação teria sofrido o recorte e, nesse sentido, considerada especial em razão da restrição característica de seus sujeitos ou alunos? Se for aceita essa possibilidade, pode-se inferir que a educação especial tenha sido a resposta possível às características especiais de seu público alvo. Seus defensores argumentariam favoravelmente à permanência de suas tradicionais funções, tendo em vista a possibilidade de oferecer-lhes melhor qualidade, a partir da relação direta entre as características dos alunos e a especialização dos serviços prestados. Esta é uma interpretação considerada técnica. Suas implicações atingem tanto as instituições que a realizam, como as valorações ética, política e profissional que se lhe atribui. Neste caso, as instituições educacionais especiais teriam ideologias distintas das demais escolas. Contraditoriamente à sua condição de especial, não lhes seria exigido cumprir objetivos pré-fixados, tampouco prestar contas quanto à eficiência, à eficácia e à efetividade de seus serviços. Isso equivale dizer que não the caberia sofrer processos de avaliação quanto à qualidade, quer do trabalho prestado, quer do processo de aprendizagem dos alunos. Uma vez consideradas especiais, essas instituições teriam funções diferentes daquelas da educação geral.

Outra implicação decorrente da versão mecaniscista da educação especial é sua consideração como objeto científico menor, irrelevante e incompleto. Nessa perspectiva, são secundários, portanto menores em importância e significação social, tanto a instituição educacional como os sujeitos que apresentem necessidades especiais. Aos professores envolvidos nessa modalidade de educação, ainda que percebam gratificações para o exercício de sua atividade nesse campo, não lhes é exigido um processo de reciclagem pedagógica permanente, nem um compromisso político firmado com a apropriação dos saberes socialmente produzidos, e, por conseqüência, o exercício da cidadania dessas pessoas.

Se se pode aceitar que toda ciência que nasce e se consolida a partir de uma necessidade social, a educação especial, na perspectiva tecnicista, não ofereceria razões suficientes para se empreender pesquisas e se fixar, por exemplo, como objeto científico, o processo de ensino-aprendizagem. Se aceitar que a pedagogia 
somente recebeu seus fundamentos científicos a partir do imperativo posto pela Idade Moderna da educação "para todos", a educação especial, contrariamente, não sofreu, até poucos anos, implicações sociais, econômicas, políticas e culturais significativas para se pôr a necessidade e emergência de educar todos os sujeitos que apresentem características chamadas especiais. Enquanto a era da industrialização impôs a necessidade da educação da maioria dos trabalhadores, e, por conseqüência, justificou o investimento na realização de pesquisas educacionais, a educação especial surgiria com uma finalidade diametralmente oposta à educação geral. Firmava-se a era da institucionalização das pessoas que apresentassem algum tipo de deficiência.

Trata-se de questionar também, que razões justificaram a consideração de cegos, surdos, deficientes mentais e outros como sujeitos especiais e diferentes de outros segmentos sociais que poderiam ser, porém não foram, considerados especiais, tampouco submetidos a essa particular cosmovisão, ou seja, a organização e institucionalização da educação especial. A idéia de "educação", apesar de sua adjetivação especial, teria sido elaborada com finalidades semelhantes à educação pensada e organizada para os demais trabalhadores, ou serviria para mascarar as implicações clínicas desse conceito?

Se o critério para afirmar a singularidade educativa desses sujeitos é o de uma caracterização excludente a partir da deficiência que possuem, então não se está falando de educação, mas de uma intervenção; se se acredita que a deficiência, por si mesma, em si mesma, é o eixo que define e domina toda a vida pessoal e social dos sujeitos, então não se estará construindo um verdadeiro processo educativo, mas um vulgar processo clínico. (SKLIAR, 1997, p. 9)

Com efeito, tomar a deficiência como critério para se levar a cabo o processo de institucionalização, não atribui à modalidade de educação que vier a ser organizada para essas pessoas a caracterização de especial. Qual a razão para considerá-la especial?

Por outro lado: em que sentido falar de uma instituição escolar especial? Se é porque contém fisicamente aqueles sujeitos especiais, então não se trata de uma escola, mas de um hospital. Se, por outro lado, se trata de que as instituições são especiais porque pretendem desenvolver uma didática especial para aqueles sujeitos deficientes, então pode ocorrer que, em vez de processos interativos de educação exista uma aplicação sistemática de recursos, exercitações e metodologias neutras e desideologizadas. (SKLIAR, 1997, p. 10)

Historicamente, pode-se encontrar nas relações entre a presença da deficiência e o processo de institucionalização nos leprosários e, em seguida, em grandes hospitais europeus que abrigavam pessoas com diferentes rotulações e estas justificavam sua segregação para a preservação daquela ordem social. A idéia de organizar um tipo de educação e dotá-la de recursos, sistematização e metodologias poderia ter constituído avanço histórico significativo frente às velhas concepções inatistas e deterministas sobre esses seres, como seres inadaptados e menos válidos. Contudo, tal finalidade nunca fora concretizada em prol do abandono real do processo de institucionalização, o que se justifica afirmar que se isso não ocorrera, não foram organizadas práticas pedagógicas coerentes com tais finalidades ou, então, essas finalidades nunca foram proclamadas anteriormente. Por último, se a caracterização de especial estiver vinculada à idéia de educação menor, incompleta e irrelevante, confirma-se a partir do discurso aparentemente desideologizado que se difunde na organização das políticas educacionais e na realização das práticas pedagógicas nesse campo. A aparente neutralidade dos organizadores das políticas, dos dirigentes e, mesmo, dos professores vinculados a este campo da educação, transmite socialmente a mensagem de que as condições sociais de tais pessoas estejam atendidas e que, portanto, as relações sociais por elas produzidas estejam marcadas por condições de igualdade. Nesse sentido, a caracterização de especial à educação atribui aos seus agentes a função de protecionismo, assistencialismo e não a de fornecer elementos culturais essenciais rumo à emancipação desses sujeitos.

O estigma da falta de inteligência, defeito, falha, ou déficit, impõe às pessoas com deficiência a condição de seres desacreditados socialmente, o que as reduz a uma espécie de destino pré-determinado. $\mathrm{O}$ mote, citado por Ceccim (SKLIAR, 1997, p. 47), confirma algo já constatado denunciado pelas pessoas com deficiência que tomaram consciência de que "qualquer atitude de uma pessoa com DM será interpretada como originária, essencialmente, da própria deficiência.” Assim, para além da deficiência objetivamente detectável, há uma produção social da subjetividade de deficiente. Na cotidianidade, as pessoas são guiadas pelo imediato e pelas referências locais. A presença de uma deficiência suplanta qualquer concepção que se pretenda 
integral do ser humano. Toma-se, à parte, a deficiência como determinante para a formação de uma visão de todo o ser. É nesse sentido que as ações e as decisões dessas pessoas acabam por ser insignificantes diante da deficiência, a qual é isolada como determinante fundamental para uma concepção unilateral de homem. Socialmente, a deficiência teria mais importância que as atitudes dos indivíduos, suas ações e decisões não produziriam transformações no real, porque são vistos como não capazes de produzir. $\mathrm{O}$ critério que é tomado para afastá-lo da normalidade obedece a uma visão histórica da realidade, desconsiderando-se inventos e instrumentos já produzidos pela cultura humana.

\begin{abstract}
A cultura não é apenas um código comum nem mesmo um repertório comum de respostas a problemas recorrentes. Ela constitui um conjunto comum de esquemas fundamentais, previamente assimilados, e a partir dos quais se articula, segundo uma 'arte da invenção' análoga à da escrita musical, uma infinidade de esquemas particulares diretamente aplicados a situações particulares. [...] Tais esquemas de invenção também podem ter a função de remediar a falta de invenção, no sentido comum do termo. [...] Os automatismos verbais e os hábitos de pensamento têm por função sustentar o pensamento, mas também podem, nos momentos de 'baixa tensão' intelectual, dispensar de pensar. Embora devam auxiliar a dominar o real com poucos gastos, podem também encorajar aos que a eles recorrem para fazer economia da referência ao real. (BOURDIEU, 1974, p. 208)
\end{abstract}

Aos dirigentes, professores e outros profissionais, ao assumirem sua função, não se põe implícita ou explicitamente o compromisso de transformação das condições objetivas e sociais dessas pessoas.

Consta de algumas entrevistas, realizadas para este trabalho de pesquisa, algo que já é conhecido publicamente. Muitos professores não atuam conscientemente em prol da emancipação social de seus alunos que apresentem necessidades educacionais especiais. Fazê-lo, equivale a pôr em risco sua própria função. Este é mais um dado que reforça a idéia clínica da educação, tendo em vista que só se poderia aceitar uma relação direta entre agente e paciente, na perspectiva do trabalho médico.

O significado da educação especial está diretamente relacionado à concepção clínica da pessoa, na qual, a deficiência exerce o papel de determinante na relação entre o profissional e o sujeito. Porém, no momento em que a perspectiva clínica invade o campo educacional, perdem-se as especificidades de um e de outro. A manutenção da relação de dependência é o resultado possível quando os objetivos educacionais e compromissos políticos firmados com a transformação social desses sujeitos não estão produzindo práticas pedagógicas emancipadoras.

Por modelo clínico-terapêutico considero toda a opinião e toda prática que anteponha valor e determinações acerca do tipo e nível da deficiência acima da idéia da construção do sujeito como pessoa integral, apesar de e com sua deficiência específica.

A obstinação do modelo clínico dentro da educação especial nos revela um clássico problema, ainda não explicado, dentro desse contexto: a necessidade de definir com clareza se esta perspectiva educativa é aliada da prática e do discurso da medicina ou se é aliada da pedagogia ou, como muitos outros supõem, se deve existir uma combinação, uma somatória provável de estratégias tanto terapêuticas como pedagógicas. (SKLIAR, 1997, p. 10)

A predominância da abordagem clínica sobre a abordagem educacional, cumpre a exigência social de isolar as pessoas portadoras de uma condição biológico, físico e sensorial distinta para evitar a perturbação da ordem. Já a denominação e a prática de educação especial, neste determinado momento histórico, confirma a função de não educar na perspectiva de conduzir as pessoas ao processo de emancipação social. Nesse sentido, a educação social cumpre a função ideológica de formar socialmente uma representação da reparação das fraquezas e limitações sociais e humanas. O "mal da humanidade" estaria sendo sanado com a instalação de programas ditos de educação especial levadas a cabo na perspectiva clínico terapêutica.

A concepção do sujeito, a imagem de Homem, a construção social da pessoa, etc., desenvolvem-se em linhas opostas ao contrastar a versão incompleta de sujeito que oferece o modelo clínico-terapêutico e a versão de diversidade que oferec e - ou, melhor, que deveria oferecer - o modelo sócio-antropológico da educação. Disso resultam, por outro lado, conseqüências futuras bem diferentes: uma questão seria a do completamento do sujeito e outra, contrária, seria a questão do aprofundamento dos aspectos comuns próprios da diversidade cultural. (SKLIAR, 1997, p. 11) 
$\mathrm{Na}$ verdade, a abordagem clínica da educação especial se presta à função social de manter os supostamente inferiorizados, incapacitados, à margem da produção e usufruto dos bens e serviços sociais.

Fica claro que a pretensão de definir os sujeitos com alguma deficiência como pessoas incompletas faz parte de uma concepção etnocêntrica do homem e da humanidade. O etnocentrismo - junto a um de seus derivados mais perigosos na educação especial: o paternalismo - é um reflexo da intolerância e do racismo gerado por um modelo econômico-político concêntrico, que utiliza os meios de comunicação de massa ou o contrário - para exercer sua teoria e sua práxis de globalização. Então, a homogeneidade humana é a notícia e a diversidade, incluída a população especial, aparece sob forma de um assassinato, sob o rosto de uma pobreza que se sugere voluntária, da violação, etc., fatos que se consomem pelo resto da população com uma certa curiosidade e voracidade antropofágica. (SKLIAR, 1997, p. 11)

O indivíduo só existe, na perspectiva da comunicação de massa, na medida em que possa representar potencial de consumo dos produtos padronizados. A diversidade antropológica é objeto da curiosidade, e suas manifestações culturais são vistas como pitorescas, servindo para combater a tragédia do imaginário.

É nesse sentido que o discurso da medicina se torna um aliado incomparável da concepção clínica dentro da educação especial: os esforços pedagógicos devem submeter-se previamente a uma potencial - e quimérica - cura da deficiência. O questionamento implícito desta concepção seria o seguinte: se se tira ou se reduz o tamanho da deficiência, se tiram ou se reduzem as conseqüências sociais. O Homem seria Homem se não fosse surdo, se não fosse cego, se não fosse retardado mental, se não fosse negro, se não fosse homossexual, se não fosse fanático religioso, se não fosse indígena, etc. Nada mais absurdo. (SKLIAR, 1997, p. 11)

Nesta perspectiva, a cegueira, a surdez, a deficiência mental, seriam limitadores e impeditivos à conquista da condição humana. Essas condições não permitiriam a conquista da condição do ser universal, livre e consciente, própria do humano genérico. O cego, o surdo, o deficiente mental, não passariam além da condição de animal. Segundo Gagnebin:

\begin{abstract}
Assim, Platão, que nos assegura nas Leis $(808 \mathrm{~d} / \mathrm{e})$ que como as ovelhas não podem ficar sem pastor, senão se perdem, assim também que a vigie e controle em todos os seus movimentos, pois a 'criança é de todos os animais o mais intratável ('ho de pais pantôn theriôn esti dusmetacheiristotaton'), na medida de seu pensamento, ao mesmo tempo cheio de potencialidade e sem nenhuma orientação reta ainda, o torna ardiloso, o mais hábil e o mais atrevido de todos os bichos' ('epiboulon kai drinu kai hybristotaton theriôn gignetai'). (GHIRALDELLI, 1997, p. 85)
\end{abstract}

A pessoa com deficiência é afastada da "normalidade da razão", própria da idade adulta, e, ao mesmo tempo, considerada uma ameaça a uma pretensa ordem e harmonia sociais.

"Essa criança ameaçadora na sua força animal bruta, essa criança deve ser domesticada e amestrada segundo normas e regras educacionais fundadas na ordem da razão (logos) e do bem tanto ético quanto político, em vista da construção da cidade justa.” (GHIRALDELLI, 1997, p. 86)

A pessoa com deficiência teria toda sua produção, toda sua vida relacionada à condição física imediata.

$\mathrm{O}$ animal produz unilateralmente, enquanto o homem produz universalmente; produz unicamente devido à necessidade física imediata, enquanto o homem produz inclusive livre da necessidade física e só produz realmente liberto dela; o animal produz só a si mesmo, enquanto o homem reproduz a natureza inteira; o produto do animal pertence imediatamente a seu corpo físico, enquanto o homem se enfrenta livremente com seu produto. $\mathrm{O}$ animal cria unicamente segundo a necessidade e à medida da espécie a que pertence, enquanto o homem sabe produzir segundo a medida de qualquer espécie e sabe sempre impor ao objeto à medida que lhe é inerente; por isso o homem cria também segundo as leis da beleza. (ENGUITA, 1993, p. 104 )

Na perspectiva local, alienada e imediata, a pessoa não produziria livre e universalmente; a pessoa com deficiência, ao invés de impor-se ao objeto, estaria submissa a ele, presa e limitada.

Não há nenhuma relação entre a deficiência e seus supostos derivados sociais diretos, pois estes não são uma conseqüência direta daquela, mas sim das formas e dos mecanismos em que estão organizadas e de 
que dispõem as sociedades para não exercer restrições no acesso a papéis sociais e à cultura das pessoas, de todas as pessoas. De fato, duas pessoas com idênticas deficiências, e que vivem em sociedades diferentes, possuem, obviamente, trajetórias de desenvolvimento diferentes. O papel que desempenha uma deficiência no começo da vida de um sujeito não é de ser o centro inevitável de seu desenvolvimento, mas, pelo contrário, a força motriz de seu desenvolvimento. (SKLIAR, 1997, p. 12)

A deficiência exerce uma dupla função sobre o processo de desenvolvimento. A função limitadora conjuga-se com a função fortalecedora do indivíduo. Segundo VYGOTSKY (1989), aceitar a deficiência e tomar consciência de um certo sentimento de inferioridade atribui ao indivíduo um instrumento de força superior ao próprio sentimento. Segundo Adler, citado pelo autor:

O sentimento de uma perturbação constitui o estímulo constante para o seu desenvolvimento do psiquismo. Sentimento de um órgão defeituoso constitui o estímulo constante para desenvolvimento psíquico do indivíduo. O defeito determina a orientação das formas psíquicas e, bem como as vias para o sucesso do processo de crescimento e de formação da personalidade.(VYGOTSKY, 1989, p. 6).

\section{E o próprio VYGOTSKY acrescenta:}

A posição social conscientemente avaliada constitui-se a força do desenvolvimento psíquico. Os mecanismos funcionais como a memória, a intuição, a atenção, a sensibilidade e o interesse frente às adversidades enfrentadas conduzem à constituição de uma super resistência e à transformação de inferioridade em superioridade, a incapacidade em competência e talento. (VYGOTSKY, 1989, p. 6)

Este é o princípio antropológico segundo o qual as resistências naturais se convertem dialeticamente em transformações recíprocas, gerando, ao mesmo tempo técnicas em instrumentos objetivos, de um lado, e saberes, capacidades e competências subjetivos, de outro.

Essa perspectiva dialética, - negação da negação, instaurada individual e socialmente - é possível a partir das leis da contradição, movimento e da relação. Já, do ponto de vista biológico, tal questão é esclarecida na seguinte afirmação de SKLIAR:

O cérebro dos primeiros anos de vida é de tal flexibilidade e plasticidade que só uma profunda e errada abordagem clínica negaria todo o potencial de compensação que se reúne na direção contrária ao déficit. Em outras palavras, a criança não vive a partir de sua deficiência, mas a partir daquilo que para ela resulta ser equivalente funcional. Tudo isto seria certo se, desde já, o modelo clínico-terapêutico não se obstinasse tanto em lutar contra a deficiência, o que implica em geral originar conseqüências sociais ainda maiores. Reeducação ou Compensação, essa é a questão. Obstinar-se contra o déficit, esse é o erro. (1997, p. 12)

Neste caso, a deficiência é, ao mesmo tempo, um desvio da norma social e algo a ser naturalizado. Nesse sentido, o limite é natural; a existência de barreiras arquitetônicas e pedagógicas é natural; o isolamento e a não oportunidade de acesso à produção cultural são naturais.

É evidente que o ser humano só se constitui progressivamente, no curso de um longo devenir que se inicia com o nascimento para só acabar na maturidade. Suponha-se, porém, que esse devenir nada mais faça que atualizar virtualidades, retirar reluzentes energias latentes que já existiam [...]. O educador não teria, portanto, nada de essencial a acrescentar à obra da natureza. Não criaria nada novo. Seu papel limitar-se-ia a impedir que essas virtualidades existentes se atrofiassem devido à inação, ou se desviassem de seus cursos normais, ou se desenvolvessem com muita lentidão. (GHIRALDELLI, 1997, p. 75)

A organização de práticas e a teorização dessas práticas, caracterizada pelas baixas expectativas dos professores em relação aos alunos que apresentem necessidades especiais, também são consideradas naturais.

Para muitos, o fracasso educativo massivo se traduz na verdadeira obrigação de pensar que são as próprias limitações dos sujeitos educativos o que origina esse fracasso.

Entretanto, existe uma interpretação alternativa contra esse fácil silogismo. Se a escola especial parte do pressuposto de que os sujeitos estão naturalmente limitados, toda a orientação educativa está obrigada a orientar-se naturalmente em direção a essa idéia e os resultados, finalmente, concorrem com essa percepção. Através dessa particular perspectiva, o círculo das baixas expectativas se fecha com uma 
notável facilidade: os magros resultados são um produto direto da inconsistência dos próprios alunos e não da natureza do projeto educativo. Não há que se ruborizar se se afirma que, na realidade, o fracasso é resultado de uma pressão metafísica que se exerce sobre os sujeitos especiais: eles estão presos por uma falsa concepção ideológica/pedagógica, estão condicionados a respirar através de falsas representações sociais, regulados por meios de normas e hábitos medievais, não podem comunicar-se pois têm que aprender como superar a deficiência e ser iguais aos demais - onde estão e quais são os demais? - em vez de jogar, repetem, em vez de mover-se, exercitam-se.

Há uma certa hipocrisia quando se atribui toda a responsabilidade do fracasso da educação especial, justamente, aos alunos especiais. O fracasso é o resultado de um complexo mecanismo que reúne fatores sociais, políticos, lingüísticos, históricos e culturais, e que provém daqueles profissionais que, dando-se conta ou não, voluntariamente ou não, representam e reproduzem a idéia de um mundo homogêneo, compacto, sem variações, sem fissura. (SKLIAR, 1997, p. 12-13)

$\mathrm{Na}$ verdade, os fracassos não são tomados como tais. São tidos como naturais. São os resultados da inconsciência dos alunos. O processo pedagógico em curso é apenas um ritual para confirmar a cotidianidade imutável dessas pessoas.

A concepção de educação que toma o desenvolvimento humano como sucessão de etapas progressivas de um possível curso natural da vida e das coisas, reforça a manutenção da condição a priori limitada e limitadora dos sujeitos com necessidades especiais. Nesta perspectiva, espera-se que as capacidades de cada um se potencializem naturalmente. A proclamada desigualdade natural entre estes sujeitos seria justificada pelas diferenças intrínsecas e não pelas diferenças e mediações culturais e sociais existentes nas relações entre os sujeitos.

Esses sujeitos estão condicionados a pensar e agir segundo representações daqueles que, em não apresentando uma deficiência aparente, se defendem contra os que a apresentem para não revelar suas próprias deficiências, aquelas não aparentes.

Da pretensão à normalidade surge o individualismo.

Cada uma por si. Deus por todos. Esta é a frase-tema do individualismo. Torna-se convincente e simpática quando justifica o argumento de que, se uma família tem filhos perfeitos, seu compromisso social e humano se resume a cuidar bem deles. Evitar que se tornem um peso para a comunidade. Prepará-los para produzir. E para gerar novos descendentes, igualmente saudáveis, que férteis se reproduzirão, perpetuando como educadores a mesma linha individualista na condução da prole.

Por esse caminho chegaremos à sociedade inclusiva? Não. Cuidar apenas da educação dos nossos próprios descendentes não deve mais nos satisfazer. Os problemas de uns têm de ser os problemas de todos.

Social e politicamente, o reflexo mais óbvio da cultura do individualismo é a exclusão das minorias. Minorias no sentido dos desfavorecidos pela legislação de seu país ou pelas posturas e decisões de sua comunidade.

Cada um de nós é perito na arte de disfarçar nosso desejo de excluir. Ou de achar que as soluções para a não violação de direitos virão como mágica. (WERNECK, 1997, p. 162-164)

Ao tomar o processo de exclusão como algo que se tornou habitual por estar incorporado à cultura individualista, atribui aos sujeitos humanos uma condição mecânica e linear, segundo a qual, a naturalização do modo de pensar e agir próprio do senso comum determina, em última análise, a exclusão das pessoas com deficiência. Ao situar no indivíduo tanto a responsabilidade pela exclusão social como o dever de superá-la por conta da adoção de comportamentos de solidariedade e cooperação, processa-se o desvinculamento entre o problema da exclusão social, sua superação e o modo como se organiza estrutural e politicamente a sociedade. Analogamente, pode-se afirmar que a simples convivência entre brancos e negros, por exemplo, possa determinar a crise na sociedade individualista e, por conseqüência, a crise dos preconceitos, ou seja, sua superação.

Há apenas governos mais ou menos preocupados em seguir a linha do politicamente correto.

Com a crescente autonomia dos jovens adultos com Síndrome de Down no Brasil e no mundo a cultura do individualismo está em crise. Mesmo poucos, estão em número suficiente para desestabilizar a rotina de relações pessoais e sociais entre nós e eles, entre eles e seus governos, rotina inspirada na cultura da tolerância. Tolerar é permitir, com ressalvas. Quem permite não pode ser incomodado com grandes reformulações de pensamentos e de atitudes.

Inclusão e individualismo são posturas incompatíveis. 
Para combater o individualismo a humanidade deve perceber que a deficiência é uma questão humana. Tão humana quanto o sentimento de individualismo que nos faz esquecer disso. (WERNECK, 1997, p. $165)$.

Valendo-se de uma visão individualista de sociedade, WERNECK se sensibiliza com o esforço percebido por ela nas pessoas com deficiência para garantirem sua existência, apontando a necessidade de que os "normais" ou os "dominantes" também se esforcem para estabelecer elos de comunicação e intercâmbio com os "dominados". Ela assume a perspectiva de que as relações de poder se reproduzem nas diferentes relações sociais em cuja corrente encontram-se as pessoas com deficiência na condição de dominados. Os "dominantes" passam a ser referência para os "dominados". WERNECK é contundente ao afirmar a necessidade dessas pessoas estabelecerem canais sólidos de comunicação, liberdade de pensamento e expressão, serem ouvidas e partícipes da direção dos processos sociais. Tal consideração, a seguir, tem particular importância em razão de se tratar de um profissional sem os clássicos vínculos de atendimento às pessoas com deficiência, que consegue perceber, contudo, as diferentes formas de opressão e de morte de suas individualidades. Começa, assim, o resgate antropológico desses sujeitos, sem que isto venha a se chamar sociedade inclusiva. Merece destaque a riqueza e a sensibilidade de seu pensamento: “[...] para mim, está relacionado a algo além do que apenas abrirmos e oficializarmos espaços para que pessoas com comprometimento intelectual se expressem. O grande salto é aprender a ouvi-las. Quanto mais legítimo for esse processo, mais iremos descaracterizá-las como seres passivos [...]. (WERNECK, 1997, p. 168-169)

As pessoas que apresentem tais necessidades especiais não podem pensar o que pensam, nem expressar os saberes extraídos de suas experiências, mas pensar e expressar apenas o conteúdo daqueles que os conduzem. Como não são conduzidos rumo ao desvelar do real e à apropriação dos princípios e fundamentos das ciências, da comunicação e da natureza, esses indivíduos devem permanecer na "mesmice", o território local de suas individualidades físicas, semelhante à condição dos animais.

\begin{abstract}
A diferença colocada por Marx entre o animal que se reproduz a si mesmo e o homem que reproduz a natureza inteira só pode ser compreendida atentando-se para o aspecto consciente que distingue a produção humana da animal; efetivamente, o homem, no seu trabalho produtivo, propõe-se a conservar ou modificar a natureza, coisa que não se pode dizer do animal. É neste sentido que se pode afirmar que o produto do animal se incorpora imediatamente a este, enquanto o homem se enfrenta com seu produto como algo distinto, objetivado, ou que o animal produz unilateralmente - segundo sua própria medida - e o homem universalmente - sem limites, ou sem outros limites que os da própria natureza em si. (ENGUITA, 1993, p. 104)
\end{abstract}

Gagnebin encontra na república de Platão, depois da famosa "Alegoria da Caverna”, a afirmação enfática da capacidade de aprender humana, faculdade inata e universal em todos, mesmo que não sempre na mesma proporção. Esse idealismo responde à pré-concepção das características intrínsecas das pessoas como pré-requisito para sua educação. As rotulações e classificações das pessoas seriam conseqüência natural das diferenças. Assim diz Platão:

A educação (paidéia) é, portanto, a arte que se propõe este fim, a conversão (periagoge) da alma, e que procura os meios mais fáceis e mais eficazes de operá-la; ela não consiste em dar a vista ao órgão da alma, pois que este já a possui; mas como ele está maldisposto e não olha para onde deveria, a educação se esforça por levá-lo à boa direção.(GHIRALDELLI, 1997, p. 86)

Mas uma das razões para a perpetuação da concepção clínica na educação especial é a ausência da reflexão de caráter educativo sobre os princípios e finalidades que regem este campo científico. Trata-se do exercício da auto-reflexão, na qual são analisados e questionados os procedimentos e conteúdos do tipo do trabalho historicamente levado a termo junto às pessoas com necessidades especiais. A análise e o questionamento quanto à natureza técnica e política das escolhas realizadas, as estruturas arquitetônicas e pedagógicas e de serviços organizados, o grau de participação dos pais, comunidade e pessoas com necessidades especiais nos processos decisórios, quer no planejamento, quer no acontecimento desse tipo de educação, necessitam constar das pesquisas e dos debates de todo o sistema educacional, em todos os seus níveis. Discutir suas especificidades e os pressupostos que governam a educação das pessoas que apresentem necessidades educativas especiais é uma urgência, um dever e um direito do Estado, família e sociedade, no mesmo grau de interesse, respeitabilidade e valoração ética que o problema da educação das crianças de rua, 
dos filhos dos sem terra, dos próprios sem terra e da educação de outras minorias. Se, de um lado, esses segmentos sociais possuem especificidades metodológicas, de outro, possuem um traço comum. São minorias que sofrem o processo de exclusão social que se expressa nas oportunidades educacionais, nas relações de trabalho e no acesso aos bens e serviços culturais.

\begin{abstract}
A fronteira entre educação e educação especial constitui, desse ponto de vista, uma primeira discriminação: a de impedir que a pedagogia especial discuta afazeres educativos; a de ter que, como conseqüência, refugiar-se e envergonhar-se como se se tratasse de um tema sem importância. $\mathrm{O}$ fato de que a educação especial está virtualmente excluída do debate educativo é a primeira e mais importante discriminação sobre a qual, depois, se projetam sutilmente todas as demais discriminações - por exemplo, as civis, legais, laborais, culturais, etc. Entretanto, não estou falando simplesmente do direito à educação que também assiste aos surdos; não é que as crianças especiais têm que ir, como todos os demais, à escola, à instituição escolar entendida como um ente físico, material. Estou afirmando que esse direito deve ser analisado, avaliado e planificado conjuntamente a partir do conceito de uma educação plena, significativa, justa, participativa; sem as restrições impostas pela beneficiência e a caridade; sem a obsessão curativa da medicina; evitando toda generalização que pretenda discutir educação só a partir e para as míticas crianças normais. (SKLIAR, 1997, p. 14)
\end{abstract}

Impor a educação especial à ditadura do modelo médico-clínico, significa a lei do silêncio, da subserviência e a anulação de seu caráter político, científico e profissional. Trata-se do exercício de uma função que discrimina e segrega tanto seus agentes como seus alunos. Contra a lei do silêncio e da subserviência, não se pode erguer nenhuma voz, não se pode reivindicar nenhum direito; contra a ausência do caráter profissional da educação, não se pode requerer a apropriação dos saberes acumulados, tampouco organizar as situações educativas para criá-los ou produzi-los; diante da aparente neutralidade política, as desigualdades não podem ser questionadas, pois são todas elas mascaradas, negadas e proclamadas na forma da igualdade entre todos.

O cidadão-pela-metade será um profissional despreparado. Violará pequenos e grandes direitos das pessoas com deficiência e talvez morra sem perceber isso. [...] Quando o adulto nega a seus filhos o direito de receberem informações sobre o que ele considera serem anormalidades, pratica uma das formas mais sutis de discriminação. Ao optar por só falar do bom, do bonito e do belo, o adulto vira um deturpador da realidade. Passa a sonegar dados sobre um mundo real (nele estão incluídas as doenças e as deficiências) que as crianças percebem como sendo parte do mundo delas, mas que nós insistimos em ignorar ou esconder.

Aprender sobre artrite, diabetes, hemofilia, paralisia cerebral, lábio leporino, gagueira, dislexia, ostomia, dislalia, doença renal, epilepsia, paraplegia, cegueira, surdez, alergias alimentares, câncer, prevenção de deficiência é útil para a formação de um cidadão?

Defendo que sim. Essas informações fazem parte da construção da cidadania. [...]

As crianças de hoje são muito espertas. Nós ainda não somos. Por isso, quando a garotada nos interroga sobre temas relacionados à deficiência raramente associamos tal interesse à inteligência e à precocidade intelectual.

Eu sei, nada é tão simples. Mas é também por não termos sido educados para entender a diversidade como situação natural da vida que hoje lutamos em seguir regras que dêem ao indivíduo com deficiência direitos assegurados na Constituição Brasileira.

Por isso acredito na força de um lar transformador. Nele, quando questionados sobre temas que lhe incomodam, os adultos abrem seus dicionários e... seus corações. (WERNECK, 1997, p. 140-141)

Discutir coletivamente o direito à educação e à participação é mais do que incluir as pessoas, em suas diversidades, no mesmo ambiente escolar. Discutir o direito à educação plena é questionar modelos protecionistas, a natureza e as implicações da beneficência, do autoritarismo, das relações arcaicas do poder e das formas de exclusão. Incluir a pesquisa e o debate sobre o direito à educação plena dessas pessoas ditas especiais, sob condição de que estes participem ativamente, trata-se de pôr em marcha a estratégia social mais transformadora e agregadora de direitos. Na medida em que o homem submete sua ação produtiva a um projeto consciente, deixa de ter uma existência limitada ao fenomênico e se manifesta como ser livre.

O homem é um ser genérico não só porque na teoria e na prática toma como seu objeto o gênero, tanto o seu próprio como o das demais coisas, mas também, e isto não é mais que outra expressão para a mesma 
coisa, porque se relaciona consigo mesmo como gênero atual, vivente, porque se relaciona consigo mesmo como um ser universal e por isso livre." (ENGUITA, 1992, p. 105)

Tal como o homem se produz como um ser livre, o faz como um ser político. Ser cidadão significa compartilhar dos bens sociais, o que supõe participação

[...] na esfera da existência política. O tecido social é atravessado pelas relações de poder, ou seja, os homens não se relacionam automaticamente entre si por relações de igualdade; ao contrário, perpassam, entre eles, relações de poder que se transmutam muito facilmente em relações de dominação, de opressão, de exploração. (SEVERINO et al., 1992, p. 11)

Ao se afastar da educação geral e ao eliminar a perspectiva auto-reflexiva, a educação especial tende a fixar-se sobre os problemas imediatos que são, obviamente, aqueles relacionados à condição biológico-físicosensorial de seus alunos. A ênfase no trabalho coletivo é centrada em atividades que se prestam à manutenção das pessoas em sua localidade imediata. O problema que lhes é imediato e aparente é uma suposta imcompletude dos alunos, porque justifica a existência de um trabalho para corrigir a aparente não integração dos sujeitos. A necessidade de adotar uma concepção corretiva desse modelo de educação, obriga os profissionais a se dedicarem na busca tão-somente de recursos, metodologias e técnicas as quais deverão ser aplicadas, desvinculadas de um compromisso político, quer dos profissionais, quer dos sujeitos que apresentem as necessidades educacionais especiais. A neutralidade deve ser o princípio orientador do trabalho. Reflexão para quê? Refletir, debater, rever objetivos, princípios e finalidades poderia pôr em xeque as velhas formas de organização do trabalho educacional, quer o especial, quer o geral. Uma demonstração da falta de crítica e reflexão no trabalho pedagógico é o modo como se encaminha a questão da linguagem na educação de surdos e a educação dos cegos. Questões de tamanha relevância se restringem, na maioria das vezes, às discussões exclusivas entre ouvintes e videntes, sendo excluídos os principais interessados. Esse processo de exclusão de surdos e cegos sobre questões educativas que lhes dizem respeito é uma demonstração tanto do atraso científico neste campo quanto do autoritarismo e poderio débil que caracteriza relações sociais estruturadas sob formas arcaicas, resultados de relações pedagógicas que excluem os verdadeiros sujeitos do processo educativo como surdos, cegos e outros, aparecem na forma do fracasso escolar, da evasão e da não conquista da cidadania por esses sujeitos. Essa é uma patética amostra da incapacidade dos ouvintes e videntes de ouvir e aprender com as experiências acumuladas por séculos e séculos de surdez, cegueira e de outras deficiências ou necessidades especiais. Estas são experiências individuais e coletivas, locais e universais que não podem jamais ser subestimadas ou substituídas tãosomente pela visão técnica.

Aquilo que aparece como neutralidade do currículo na educação especial é, na verdade, uma organização intencional para manter os sujeitos marginalizados da informação e destituídos de identidade cultural e social. É preciso que se assuma uma neutralidade científica e cultural para que os sujeitos que apresentem necessidades especiais dimensionem suas reais necessidades que são políticas, de conhecimento, de trabalho e de cidadania. Portanto, são necessidades que vão além daquelas vinculadas ao seu equipamento biológico-físico-sensorial.

A consideração ampliada de tais necessidades vem sendo interpretada como necessidade de integração física de tais pessoas no sistema geral de educação.

Contudo, é certo que as políticas inclusivas de tais pessoas resultam de constatações de sérios problemas na educação especial. Seus resultados têm sido limitados, assim como são poucas as pessoas que se emancipam das práticas assistencialistas e caritativas alcançando condição de cidadania real e plena. A integração física dessas crianças em escolas comuns seria um avanço, mas, ao mesmo tempo, a perda de especificidades metodológicas já construídas historicamente. A desconsideração de um conjunto de experiências profissionais já acumuladas, ainda que marcadas pelo viés tecnicista e clínico da educação especial, pode trazer aos novos profissionais responsáveis pela educação dessas crianças funções para as quais podem alegar não terem sido preparados. A justificativa centrada no processo de formação profissional pode ser o ponto de apoio para a adoção de novas práticas consideradas neutras, acríticas e marcadas por novas formas de assistencialismo. O descompromisso político poderá ser encoberto com aumentos e fatos convincentes no plano do discurso ideológico, ou seja, as crianças estão, agora, incluídas no mesmo ambiente escolar de todos.

VYGOTSKY (1989, p. 8) afirma que os estigmas resultantes do processo de institucionalização da pessoa com deficiência provoca o enfraquecimento de sua posição social sendo esse um estímulo para se forjar um 
ser único, ou seja, integrado social e culturalmente. É, pois, no processo da vida social coletiva que se edificam, que se desenvolvem todas as formas superiores de atividade intelectual características do homem. $\mathrm{O}$ processo histórico instrumental de educação e mediação entre as gerações e as culturas obedece ao princípio histórico de transformação, contrário às leis do desenvolvimento biológico e à hereditariedade, que obedecem ao inatismo.

Este é o princípio antropológico segundo o qual as resistências naturais se convertem dialeticamente em transformações recíprocas gerando, ao mesmo tempo, técnicas em instrumentos objetivos, de um lado, e saberes, capacidades e competências subjetivas, de outro. Qual é a condição para chegar aos objetivos? A existência de obstáculos.

As pessoas com deficiência necessitam se liberar dos quadros restritivos que supostamente a natureza lhes fixou. Neste sentido, é essencial que a educação seja organizada com vistas à formação das pessoas plenamente valorizadas do ponto de vista social. O ponto de partida é livrá-las da condenação à inferioridade.

Em última análise, o grau das expectativas e exigências sobre a pessoa com deficiência determina a qualidade de sua educação e o estágio de seu desenvolvimento. Os imperativos sociais materializam a transformação da condição de desvantagem, desigualdade ou inferioridade em impulso e força.

\section{REFERÊNCIAS}

BOFF, L. Nova Era: a civilização planetária. 2.ed. São Paulo: Ática, 1994.

BOURDIEU, P. A Economia das trocas simbólicas. São Paulo: Perspectiva, 1974.

ENGUITA, M. F. Trabalho, escola e ideologia: Marx e a crítica da educação. Porto Alegre: Artes Médicas Sul, 1993.

GHIRALDELLI Jr., P. (Org.). Infância, escola e modernidade. São Paulo: Cortez, 1997.

PESSOTTI, I. Deficiência mental: da superstição à ciência. São Paulo: T. A Queiroz, 1984.

SKLIAR, C. (Org.). Educação e exclusão: abordagens sócio-antropológicas em educação especial. Porto Alegre: Mediação, 1997.

VYGOTSKY, L. S. Fundamentos da defectologia. Haban: Pueblo y Educación, 1989.

WERNECK, C. Ninguém mais vai ser bonzinho na sociedade inclusiva. Rio de Janeiro: WVA, 1997. 